3. Sobue Y, Watanabe E, Ichikawa T, et al. Physically triggered takotsubo cardiomyopathy has a higher in-hospital mortality rate. Int $J$ Cardiol. 2017;235:87-93. doi:10.1016/j.ijcard.2017.02.090.

4. Yalta K, Yalta T. Physically triggered takotsubo cardiomyopathy has a worse prognosis: potential roles of systemic inflammation and coronary slow flow phenomenon. Int J Cardiol. 2017;242:31-32. doi:10. 1016/j.ijcard.2017.03.082.

5. Kawaji T, Shiomi H, Morimoto T, et al. Clinical impact of left ventricular outflow tract obstruction in takotsubo cardiomyopathy. Circ J. 2015;79(4):839-846. doi:10.1253/circj.CJ-14-1148.

6. Montone RA, Galiuto L, Meucci MC, et al. Coronary slow flow is associated with a worse clinical outcome in patients with takotsubo syndrome. Heart. 2020. doi:10.1136/heartjnl-2019-315909. [Epub ahead of print]

7. Yalta K, Sivri N, Yalta T. Neuropeptide Y-induced coronary microvascular dysfunction: a significant contributor to the adverse outcomes in stress cardiomyopathy? Int J Cardiol. 2011;147(2):284. doi:10.1016/j.ijcard.2010.09.095.

8. Yalta K, Yilmaztepe M, Ucar F, et al. Coronary slow flow in the setting of tako-tsubo cardiomyopathy: A causative factor? An innocent bystander? Or a prognostic sign? Int J Cardiol. 2015;198:229-31. doi: 10.1016/j.ijcard.2015.06.146.

\section{The authors respond}

We would like to thank the authors of the letter for their interest in our paper. ${ }^{1}$ Mental disorders are a major cause of morbidity, and patients with mental health disorders have a higher incidence of takotsubo cardiomyopathy (TC). We agree with the authors that our patient had a combination of both emotional and physical stressors. Norepinephrine and dopamine have been implicated as neurotransmitters in acute mania. ${ }^{2}$ Most TC patients recognize stress events as frightening experiences, leading to the increase of the bioavailability of catecholamines. ${ }^{3}$ Several theories suggest the importance of the catecholamine surge in the pathogenesis of TC. ${ }^{4}$ Our patient abruptly stopped her prescribed medications for bipolar disorder, which led to her acute manic attack and contributed to her emotional and psychological stress. Her acute mania manifested as sleep deprivation and poor oral intake, which resulted in rhabdomyolysis as a physical stress likely triggering the abrupt increase in catecholamine levels.

As mentioned by the authors, severe adrenergic discharge might be associated with malignant arrhythmia. Fortunately, our patient did not have any documented arrhythmia during her hospitalization or as an outpatient. Her echocardiogram also did not show left ventricular outflow tract obstruction.

Coronary microvascular dysfunction has been suggested as the underlying mechanism in some TC patients and has been reported in multiple diagnostic tools. ${ }^{5}$ Conflicting results have been reported regarding reduced Thrombolysis in Myocardial Infarction (TIMI) frame count in TC patients for assessing microvascular dysfunction. ${ }^{6,7}$ Our patient's coronary angiography showed normal filling in the left anterior descending artery, in the left circumflex artery, and in the right coronary artery.

Given the chronic nature of psychiatric illnesses with the risk of acute flare-ups, TC has a higher recurrence in these patients. ${ }^{8,9}$ As such, a patient-centered multidisciplinary approach including a primary care physician, cardiologist, and psychiatrist should be emphasized in the care of these patients with close follow-up to avoid further acute psychiatric attacks and decrease the rate of TC recurrence. Our patient did not have recurrence after her initial episode of TC. Therefore, invasive treatments including sympathetic ganglion blockade were avoided and not considered at the time. Unfortunately, there are no current trials evaluating the treatment of TC, and guideline-directed medical therapy for heart failure is the current standard of care for TC patients.

—Amr Idris, MD and Karim M. Al-AzIzI, MD
The Heart Hospital Baylor Plano, Plano, Texas
E-mail: karim.alazizi@bswhealth.org

1. Idris A, Christensen JL, Hamandi M, et al. Takotsubo cardiomyopathy and acute manic attack. Proc (Bayl Univ Med Cent). 2020;33(1): 80-82. doi:10.1080/08998280.2019.1686912.

2. Steptoe A, Kivimäki M. Stress and cardiovascular disease. Nat Rev Cardiol. 2012;9(6):360-370. doi:10.1038/nrcardio.2012.45.

3. Kurita M. Noradrenaline plays a critical role in the switch to a manic episode and treatment of a depressive episode. Neuropsychiatr Dis Treat. 2016;12:2373-2380. doi:10.2147/NDT.S109835.

4. Pelliccia F, Kaski JC, Crea F, Camici PG. Pathophysiology of takotsubo syndrome. Circulation. 2017;135(24):2426-2441. doi:10.1161/ CIRCULATIONAHA.116.027121.

5. Vitale C, Rosano GM, Kaski JC. Role of coronary microvascular dysfunction in takotsubo cardiomyopathy. Circ J. 2016;80(2):299-305. doi:10.1253/circj.CJ-15-1364.

6. Khalid N, Iqbal I, Coram R, Raza T, Fahsah I, Ikram S. Thrombolysis in Myocardial Infarction frame count in takotsubo cardiomyopathy. Int J Cardiol. 2015;191:107-108. doi:10.1016/j.ijcard.2015.04.192.

7. Loffi M, Santangelo A, Kozel M, et al. Takotsubo cardiomyopathy: one more angiographic evidence of microvascular dysfunction. Biomed Res Int. 2018;2018:5281485. doi:10.1155/2018/5281485.

8. Templin C, Ghadri JR, Diekmann J, et al. Clinical features and outcomes of takotsubo (stress) cardiomyopathy. N Engl J Med. 2015; 373(10):929-938. doi:10.1056/NEJMoa1406761.

9. Nayeri A, Rafla-Yuan E, Farber-Eger E, et al. Pre-existing psychiatric illness is associated with increased risk of recurrent takotsubo cardiomyopathy. Psychosomatics. 2017;58(5):527-532. doi:10.1016/j.psym.2017.04.008.

\section{Gadolinium-induced Kounis syndrome including electrocardiographic considerations}

Gadolinium is a silvery-white metal when oxidation is removed, and gadolinium salts are used in magnetic resonance imaging. The gadolinium-based contrast mediums are the most commonly used agents in magnetic resonance angiography and for brain tumor enhancement due to their association with the degradation of the blood-brain barrier. However, nephrogenic systemic fibrosis and acute kidney injury due to primary excretion of gadolinium from the kidneys and various cardiac arrhythmias including QTc electrocardiographic prolongation and hypersensitivity reactions are occasionally encountered with use of such contrast mediums. ${ }^{1}$ 